Plomp, M.G.A., Rijn, G. van, Batenburg, R.S. Chain digitisation support by point-of-sale systems: an analysis of the Dutch product software market. International Journal of Information

\begin{tabular}{|l|l|}
$\begin{array}{l}\text { Postprint } \\
\text { Version }\end{array}$ & 1.0 \\
\hline Journal website & http://www.inderscience.com/info/inarticle. php?artid=49996 \\
\hline Pubmed link & \\
\hline DOI & $10.1504 /$ IJITM.2012.049996
\end{tabular}

This is a NIVEL certified Post Print, more info at http://www.nivel.eu

\title{
Chain digitisation support by point-of-sale systems: an analysis of the Dutch product software market
}

\author{
MARIJN G.A. PlOMP ${ }^{*}$,GLENN VAN RIJN", RONALD S. BATENBURG ${ }^{\&}$ \\ *Department of Information and Computing Sciences, Utrecht University, P.O. Box 80.089, \\ 3508 TB Utrecht, The Netherlands and Dialogic Innovation \& Interaction, \\ Hooghiemstraplein 33-36, 3514 AX Utrecht, The Netherlands E-mail: m.g.a.plomp@uu.nl \\ \# Dialogic Innovation \& Interaction, Hooghiemstraplein 33-36, 3514 AX Utrecht, The \\ Netherlands E-mail: glenn.van.rijn@gmail.com \\ ${ }^{\&}$ Department of Information and Computing Sciences, Utrecht University, P.O. Box 80.089, \\ 3508 TB Utrecht, The Netherlands E-mail: r.s.batenburg@uu.nl
}

\begin{abstract}
:
Point-of-sale (POS) systems increasingly support more retail processes than just the basic cash functionality. But to what extent do they support chain digitisation, i.e., interorganisational processes as the exchange of order and sales information? We develop a two-dimensional maturity model for categorising POS systems by their level of backward and forward chain digitisation support. Both dimensions have the same maturity scale, cumulating from internal isolated, internal integrated, external linked to external integrated.
\end{abstract}

We operationalise and apply this model to the Dutch POS system market by assessing 86 different POS solutions of 79 POS vendors. It appears that about a third of all POS systems support backward chain digitisation to the external integrated level, and forward chain digitisation to the external linked level. In some branches, chain digitisation enabling initiatives are successfully deployed, e.g., in the fashion and furniture branches where EDI initiatives are established by industry boards.

\section{INTRODUCTION}

Point-of-sale (POS) systems are computerised cash registers which are traditionally used by retailers to ring up customers' purchases. There are several advantages to POS systems. Besides the use of sales data from a POS system for marketing purposes, time consuming administrative activities like ordering, customer 
Plomp, M.G.A., Rijn, G. van, Batenburg, R.S. Chain digitisation support by point-of-sale systems: an analysis of the Dutch product software market. International Journal of Information

management, stock control, order tracking, and satisfying regulations can also be reduced. Recently, newly developed POS systems also provide the ability to connect to other systems across company boundaries, thereby enabling what we call chain digitisation. With these POS systems, automatic information exchange with wholesalers and suppliers for the exchange of, e.g., sales, order, product, and customer information is possible. By making use of this information from retailers, product suppliers can adapt production and supply of goods to the actual demand, thereby reducing the bullwhip effect (Lee et al., 1997). It is also possible to better take specific preferences of customers into account.

As in any value chain, collaboration between actors in the retail value chain (i.e., the retailers, the suppliers, and the customers) is inevitable - especially for independent retailers - to survive in the modern retail market (e.g., Daft, 2001). Due to current changes in the retail sector and in consumer behaviour, retailers are forced to collaborate more intensively with other parties (Berger et al., 2005). Supply chains tend to transform from push models into pull models where customers play a major role. This transformation requires extensive collaboration between value chain partners, likely supported with IT. The adoption of POS systems and the urgency for interorganisational collaboration and alignment in the retail sector, presents the societal relevance of this study.

While much literature exists on supply chain management and retailing in general, little research has been performed on POS systems and their role in this field. As a POS system can be considered to be the electronic backbone of a retail company, it is an important last node for chain digitisation in a value chain. At this time, little seems to be known about how POS systems support chain digitisation in practice, and what POS vendors do to innovate their software to support chain digitisation. By researching POS systems from an empirical and software vendor perspective, this paper fills an important knowledge gap.

This study concentrates on the chain digitisation enabling functionalities of POS systems. These include use of electronic product catalogues, electronic ordering, einvoicing, and automatic payments. Since these functionalities cover different processes and the exchange of different business documents between individual organisations and customers, it is likely POS systems also differ. There exist various options to enable chain digitisation, which result in different degrees of integration with the other parties in the value chain. The concept of maturity can be used to model these differences in functionality.

The aim of this research is to develop a maturity model that indicates different levels of chain digitisation support of POS systems. We present the ingredients of this model in the following two sections. First, we discuss the characteristics of a retail value chain and the specific position of the retailer in this (Section 2). Second, we describe the results of a literature study on maturity models in Section 3, and present a specific POS maturity model in Section 4. Next, we apply this model to the Dutch product software vendor market, in order to determine to what degree the existing systems actually support chain digitisation. We study POS systems as a result of product development of software vendors, including how they innovate their systems. This can be considered as a typical product software supply network (Xu and Brinkkemper, 2007; Jansen et al., 2009). The methods used for the empirical application of the model are presented in Section 5, and the results in Section 6. The 
Plomp, M.G.A., Rijn, G. van, Batenburg, R.S. Chain digitisation support by point-of-sale systems: an analysis of the Dutch product software market. International Journal of Information

Technology and Management: 2012, 11(4), 257-272

final section of this paper contains the conclusions, limitations, and some suggestions for future research.

\section{RETAIL PROCESSES AND POS SYSTEMS}

Many different processes take place within retail firms, and the value chain(s) they are part of. One model that tries to categorise and visualise various activities of a retailer, is the Retail H-model, introduced by Becker and Schütte (2004). Its name stems from the fact that in the model, the primary processes of a retailing company are portrayed as an ' $\mathrm{H}$ ' (Figure 1). The H-model consists of three parts. The 'roof' contains the control and decision functions. The foundation of the $\mathrm{H}$-model is formed by the business administrative tasks. Core business processes consist of procurement, storage, and distribution of goods.

The customer side of the model (marketing, sales, goods issuing, billing, and accounts receivable) can, together with the warehousing part, be automated with a POS system. All activities can be performed at the pay desk in the store, even with an isolated (stand-alone operating) POS system. The procurement tasks can also be implemented in POS systems.

To perform procurement activities, interaction is required with other companies. Traditionally, this interaction is performed by telephone, fax or mail. Nowadays, when both parties have automated their internal business processes with IT, this can also be achieved digitally. E-mail is a very basic example, automated information exchange by using EDI or XML are specific technologies for intercompany exchange. In the latter case, data is generated and interpreted automatically. For both messaging services, systems have to be connected to each other, typically via the internet or another network.

\section{[FIGURE1]}

Activities at the top of the model (strategic planning, enterprise/executive information systems, and controlling) can be performed through business administrative systems and/or executive information systems (Stair and Reynolds, 2003). Most POS systems are able to register accounts receivable to some degree and some POS systems can also register and manage the accounts payable. They however lack functionalities that support accounting tasks. Specific administrative systems that cover accounting functions can in most cases be linked to or integrated with POS systems.

If we now want to measure chain digitisation supporting functionalities of POS systems, we need to look at the integrated level of interorganisational relations, i.e., retailers collaborating in their value chain(s). A value chain consists of all parties that are related to the fulfilment of a customer's request (Chopra and Meindl, 2004). The retailer takes a special place in the chain from raw materials provider to the endcustomer (see Figure 2). From the retail point-of-view, important value chain partners are at the one side suppliers (e.g., wholesalers) and at the other side customers. This entails that retailers have to engage in both business-to-business (B2B) and business-to-consumer (B2C) collaboration. To make automatic B2B electronic information exchange possible, collaborating organisations need to adopt similar standards and use collaborative applications. We term this backward chain digitisation. This often requires an investment in information systems for both (or 
Plomp, M.G.A., Rijn, G. van, Batenburg, R.S. Chain digitisation support by point-of-sale systems: an analysis of the Dutch product software market. International Journal of Information

Technology and Management: 2012, 11(4), 257-272

more) parties, as suppliers frequently own advanced information systems. For B2C collaboration in retail, which we label forward chain

digitisation, e-business joint action and investments are often not required (Subramani and Walden, 2000). A retailer's customer often is a private person with limited or no information technology at all. In our view, these differences in terms of both existing infrastructure and required capabilities, justifies the two separate dimensions.

\section{[FIGURE 2]}

The next question is how both types of chain digitisation can be measured, in terms of indicators and maturity.

\section{MATURITY MODELS FOR CHAIN DIGITISATION}

Maturity models are common in IS/IT to define different - distinct - maturity levels of a process or activity (Nolan, 1979). A maturity model describes the stages through which a system, process or organisation can progress or evolve. Each level is used to characterise the state of a system, process or organisation (Clark and Jones, 1999). Two principles are often expressed by maturity models. First, maturity models assume that states evolve in a cumulative way. This means that by achieving level X, level X-1 is also fulfilled.

Adherence to the requirements of all levels below a certain level is a necessary condition for achieving a higher level (Nolan, 1979). A second principle is that maturity models have an ordinal, not a ratio scale: levels are described in words, not through strict measurements/requirements. This entails that differences between the different levels are therefore often not objective.

Maturity models have been subjected to criticism for a long time (e.g., Benbasat et al., 1984; Alonso-Mendo et al., 2009). They are criticised for being too generic, not adequately describing the development path, and lacking empirical validation (Alonso-Mendo et al., 2009). In addition, measuring maturity through a questionnaire would preclude researchers from "examining the richness of anecdotal data" (Benbasat et al., 1984). We believe however, that the different types of POSsystems (i.e., ranging from standalone systems to systems that are completely integrated with external parties, both in the direction of the supplier and in the direction of the consumer) very well fit the characteristics of a typical maturity ladder. Not claiming that every retailer's system will progress through all those different stages, we do argue that each higher stage is more mature (in terms of functionality) than its predecessor. Furthermore, we attempt to avoid some of the typical pitfalls of maturity model studies in our research method, e.g., through applying the model in practice and by conducting company visits in addition to a questionnaire.

In the academic literature, numerous maturity models regarding chain digitisation can be found (Plomp and Batenburg, 2010). For this research, we select five chain digitisation maturity models, based on three criteria. First, the models define maturity levels regarding value chain integration or automation through IT or can be directly related to the use of IT. Second, the selected models describe different levels of interaction and (electronic) collaboration between value chain partners. The third selection criterion is that they all start with an internal view and for higher levels expand to value chain partners - an external view. This selection process results in 
Plomp, M.G.A., Rijn, G. van, Batenburg, R.S. Chain digitisation support by point-of-sale systems: an analysis of the Dutch product software market. International Journal of Information

Technology and Management: 2012, 11(4), 257-272

five models: Folinas et al. (2004), Wang et al. (2004), McLaren (2006), Williamson (2007), and Schoenfeldt (2008).

As presented in Table 1, these maturity models identify three to five different stages of chain digitisation maturity and corresponding IT support.

\section{[TABLE 1]}

\section{A MATURITY MODEL FOR CHAIN DIGITISATION SUPPORT OF POS SYSTEMS}

The aim of this paper is to compare different POS systems for the Dutch retail sector with regard to the chain digitisation functionalities they offer. The four maturity levels presented above can be used to this end. We develop a maturity model, based on the existing models, that specifically looks at the different integration areas of the POS system, i.e., backward and forward chain digitisation. With this model, we can measure the chain digitisation functionalities of a POS system, and categorise and hence distinguish POS systems on their level of chain digitisation support. A graphical overview of this model is presented in Figure 3.

\section{[FIGURE 3]}

We distinguish two dimensions in the maturity model: a backward (towards the wholesaler/supplier) and a forward (towards the customer) dimension of chain digitisation. Both dimensions of the model have similar maturity levels. The first two levels are aimed at internal automation of processes. Those levels are included in the model because it can be argued that retailers first automate their own store before they focus on chain digitisation. They can, for example, automate their sales processes by implementing a POS system. Subsequently, those sales systems can be expanded with other back-office systems. Finally, the company borders can be crossed with digital connections to suppliers or consumers. This development is also described by Chen et al. (2004). The last two levels of the maturity model focus on the integration of systems from value chain partners. As the POS system is the point of departure, a 'minimalistic' POS system that is only capable of registering sales and/or customer orders is the first level of chain digitisation for both dimensions. To turn our model into a measuring instrument we define the following. Backward chain digitisation covers the degree of chain digitisation support by a POS system for processes taking place between a retailer and its suppliers. Four levels of maturity are distinguished for this dimension: • Level 1: Internal isolated. At this lowest level, the POS system is capable of ringing up sales and/or registering customer orders. All data (e.g., product information) are processed and entered manually into the system, which makes the system laborious, inaccurate, and maintenance demanding (Williamson, 2007). Each function and department within the company operates as an individual unit. The information systems used within those departments operate isolated as well, which is aptly termed 'isolated islands of IT' (Folinas et al., 2004). - Level 2: Internal integrated. At this level, the POS system is directly connected to a system that can be used for managing purchases from suppliers. It is also possible that both functions are integrated in one information system. This information system covers multiple departments and processes in an organisation. The POS system is not only capable of ringing up sales or registering customer orders; it is able to generate purchase order advices based on sales and/or stock levels. When the order is received, it is also possible to update stock levels using the purchase order. 
Plomp, M.G.A., Rijn, G. van, Batenburg, R.S. Chain digitisation support by point-of-sale systems: an analysis of the Dutch product software market. International Journal of Information

Technology and Management: 2012, 11(4), 257-272

The system is able to print, fax or e-mail order documents towards suppliers. However, suppliers are not able to enter those orders automatically into their system; the system still lacks support for data exchange with business partners.

- Level 3: External linked. In this case, there are semi-automatic connections with information systems of value chain partners. There is some collaboration with partners (McLaren, 2006) and the information system supports communication with them (Williamson, 2007). There is no automatic data exchange: human effort is still required for exchanging data between information systems of value chain partners. A retailer can, for example, receive a spreadsheet with product information from a supplier per e-mail. This product database can then be imported into the POS system. Likewise, a retailer can send an e-mail to a supplier with a purchase order generated by the POS system, which can then be imported into the supplier's information system.

- Level 4: External integrated. Systems of value chain partners are integrated with the POS system, or there are direct connections available that enable automatic and direct data exchange between the information systems of value chain partners (Williamson, 2007). No human effort is required for data exchange regarding product information, orders and order responses, and electronic packing slips or invoices. Forward chain digitisation covers the relation between a retailer and its customers: the consumers or end-users. Here, four distinct maturity levels can be distinguished as well: - Level 1: Internal isolated. As starting point, this maturity level is equal to the first level of backward chain digitisation. The POS system is only capable of ringing up sales or registering customer orders. While it is possible that there are also separate information systems for managing customer contacts or maintaining a web shop, those systems are not connected to the POS system. The system lacks support for electronic data exchange with customers or external information systems. Level 2: Internal integrated. Internal integrated refers to integration of processes and systems within an organisation. The POS system is directly connected to a system that can be used for customer relationship management (CRM). It is also possible that both functions are integrated in one information system. Payne (2002) describes that integrating CRM systems with enterprise information systems can enhance customer service. Integration of organisational processes including customer processes significantly reduces transaction costs. An internal integrated system, for example, connects the enterprise resource planning to CRM (Pant and Ravichandran, 2001). Finally, sales can be registered on a per-customer basis.

- Level 3: External linked. At this level, there are semi-automatic connections for performing B2C e-business transactions. A POS system with CRM functionalities is primarily focused on recording customer information and offline (in-store) business transactions with customers. The POS system crosses the company border to perform electronic transactions with customers. An integrated web shop is an example of a functionality which matches this maturity level. Human effort at the consumer side is required, while the web shop catalogue can be built from the POS system, and customer orders can be automatically imported from the web shop into the POS system.

- Level 4: External integrated. Here, systems of consumers are integrated with the POS system or direct connections are available that enable automatic and direct data exchange between the information systems of the retailer and the customer. This is sometimes termed silent commerce, with the typical example being an 'intelligent 
Plomp, M.G.A., Rijn, G. van, Batenburg, R.S. Chain digitisation support by point-of-sale systems: an analysis of the Dutch product software market. International Journal of Information

Technology and Management: 2012, 11(4), 257-272

fridge', that automatically orders products over the internet without human intervention (Röcker, 2010).

In the next section, we show how this model was applied to the POS systems that are available on the Dutch vendor market.

\section{APPLYING THE POS MATURITY MODEL TO THE DUTCH VENDOR MARKET}

\subsection{Data collection}

Our aim was to collect data that is representative for the whole Dutch POS system market. It was therefore imperative to collect names and contact information of as many software vendors as possible. In collaboration with the portal http://www.softwarepakketten.nl and the Dutch central industry board for retail trades (HBD) we gathered the information of many software firms. This resulted in a list of 144 POS-system suppliers. We believe that this is a virtually complete list, because the portal has already been existing for many years and functions as a meeting point for software companies and a place to promote themselves.

Furthermore, the HBD also has many contacts in the retail software world. Still, the research was broadly 'advertised' in the media and relevant professional magazines, so firms that were not listed could participate as well.

The primary form of data collection was a questionnaire. In total, the field research period lasted six months. At the start, we organised an event for which all software vendors were invited, where we asked them to complete this survey. In addition, all companies were contacted by e-mail with a request for participation. We performed numerous activities in order to maximise the response. Vendors were called to remind them, and we sent out a letter by post signed by the director of the HBD. Questionnaires were formatted using Microsoft Word and XML, and were sent by email to the suppliers. They were requested to complete the survey digitally; however, paper-based completion was also possible. Depending on the branches supported by the POS system, the questionnaire was 75-102 pages long including four pages cover and introduction. The questionnaire contained around 1,000 till 1,200 possible POS system functionalities. Not only functionalities related to sales are part of the questionnaire. Also functionalities concerning procurement, stock management, CRM and web shops are assessed. Groups of (related) functionalities were categorised and presented as separate chunks, in order to facilitate quick completion. Respondents had to indicate for each functionality whether their system supports it or not, using six different answer options.

The different options were: standard supported, partly supported, optionally supported (i.e., at a premium), supported through other software solution, not supported, and expected.

Despite the size of the questionnaire, 79 different POS suppliers filled in questionnaires for 86 different POS systems. Based on the number of suppliers - as it is unknown exactly how many software solutions there are - this amounts to a response rate of $55 \%$.

Of those 79 suppliers, 75 were visited by one of the researchers in the first half of 2009. During these company visits, a predefined protocol was completed. The protocol dealt with general questions about the POS system, and a demonstration of the software by the supplier. This demonstration was performed to check the validity of the answers given in the questionnaire. The demonstration was guided by a selection of functionalities from the questionnaire. 
Plomp, M.G.A., Rijn, G. van, Batenburg, R.S. Chain digitisation support by point-of-sale systems: an analysis of the Dutch product software market. International Journal of Information

Technology and Management: 2012, 11(4), 257-272

\subsection{Model operationalisation}

We operationalised the maturity levels of the model through 21 functionalities from the questionnaire that was sent out to the POS software vendors and the company visit protocol. We limited our use of the data to generic chain digitisation functionalities, while the original survey included many functionalities that were branch-specific or related to other functional domains. Functionalities were only judged to be supported when the related question was answered by the vendor with 'standard supported' or 'optionally supported'. When the supplier answered 'partly supported', 'supported through other software solution' or 'expected', the functionality was considered not to be present in the POS system.

The operationalisation rules used to determine the distinct maturity levels are shown in Table 2. The rules imply that the proposed maturity model is cumulative. The first level (internal isolated) is the same for both forward and backward chain digitisation support. In our view, this basic functionality is the litmus test for whether a software product should be considered a POS system.

In order to illustrate how the rules have been applied to determine the maturity level of a POS system, we provide a - fictitious - example. Suppose a POS system supports registering customer sales (the first level requirement for both dimensions), transforming purchase advices into purchase orders, registering goods using a purchase order and e-mailing purchase orders. It also supports a flexible import format, but electronically sending orders towards suppliers is not supported. Then, this POS system is rated as 'internal integrated' (Level 2) on backwards chain digitisation, as it supports all functionalities of this level, but not all of the 'external linked' level (Level 3). With regard to forward chain digitisation, the system allows for the exchange of product data to a web shop only and no further functionalities. Its maturity is therefore coded as 'internal isolated' (Level 1).

\section{[TABLE 2]}

\section{RESULTS}

Based on the rules defined in the previous section, all 86 POS systems were positioned into our maturity model. This is visualised in Figure 4.

\section{[FIGURE 4]}

The figure shows that 32 POS systems (37\%) are internally focussed only, meaning that these systems offer all functionalities up to 'internal isolated' or 'internal integrated' chain digitisation on both dimensions, but not (all) on the next 'external linked' or 'external integrated' levels. 29 POS systems (34\%) offer functionalities for linking consumers, and linking or integrating external systems from suppliers. A notable result is that none of the surveyed POS systems are on the 'external integrated' level of forward chain digitisation. Another finding is that none of the systems are 'internal isolated' only with respect to the forward chain digitisation dimension, and backward 'external integrated' at the same time. Apparently, this is a combination that is not very likely.

Although the two dimensions are not equal to ratio scale variables, we can calculate the median maturity level to get an idea of how the software packages are distributed, as the dimensions are on the ordinal level. Doing so, we see that the median score of all POS systems on backward chain digitisation is 3 or 'external linked', and on 
Plomp, M.G.A., Rijn, G. van, Batenburg, R.S. Chain digitisation support by point-of-sale systems: an analysis of the Dutch product software market. International Journal of Information

Technology and Management: 2012, 11(4), 257-272

forward chain digitisation 2 or 'internal integrated'. The largest group of POS systems (23\%) is positioned at the level of 'backward external integrated' combined with 'forward external linked'. This is closely followed by $20 \%$ of the software solutions that are positioned on the 'internal isolated' backward level and 'internal integrated' forward level. Despite the lower maturity with regard to forward chain digitisation, the systems in our sample are quite diverse in terms of their chain digitisation maturity.

Next we take a more detailed perspective on our data. We made a division into two equal groups: 41 POS systems (48\%) that match the 'internal isolated' or 'internal integrated' level of backward chain digitisation, and 45 POS systems (52\%) that are 'external linked' or 'external integrated' regarding their backward chain digitisation support. Further inspection learns that the first group of POS systems consists of: - Generic solutions that can be used by retailers in all branches.

- Solutions that are specifically suitable for the fresh food branch.

- Solutions for large retail organisations or 'POS only' solutions. POS systems for large retail organisations only cover point of sale activities. For logistical flows and other store management functionalities, they depend on applications that can be connected or integrated with the POS solution (e.g., an ERP system). The second group of POS systems consists of solutions that enable connections with external organisations. We found specific backward chain digitisation initiatives for this group, such as:

- An EDI standard set up for electronic data exchange in the fashion branch.

- An EDI standard for the furniture branch, together with an e-business portal.

- Supplier specific connections, such as for retailers in the bicycle, books, drugs, animal and DIY/ironware branches.

- Tailor-made chain digitisation initiatives, that are customer and supplier specific and established on customer's demand, designed for use in multi-store retail organisations.

- Connection to ERP systems for chain digitisation enabling functionalities, often designed for use in large retail organisations.

In addition, further statistical investigation of the POS systems' variety shows that in general, systems that support a small number of retail branches score higher on backward chain digitisation maturity (Kendall's $\tau B=-0.19$, $\mathrm{p}<.05$ ). This seems to imply that systems that are designed for a specific retail branch provide more 'depth' in terms of chain digitisation functionalities. Furthermore, POS systems customised for retailers in food have on average a lower backward chain digitisation maturity (i.e., a median of 2 on a scale from Levels 1 to 4), while for POS systems designed for the fashion branch this average maturity is higher (i.e., a median of 3.5). Finally, we found two characteristics of the vendor to be of influence on the chain digitisation maturity of the POS systems they offer. Systems supplied by POS vendors that exist longer are more mature in terms of backward chain digitisation when compared to those of 'young' POS vendors (Kendall's $\tau \mathrm{B}=0.22$; $\mathrm{p}<.05$ ). Similarly, POS vendor companies that have a larger number of employees also tend to offer more mature systems with regard to forward chain digitisation (Kendall's $\tau \mathrm{B}=0.24 ; \mathrm{p}<.05$ ).

\section{CONCLUSIONS AND DISCUSSION}

In this paper, we developed a maturity model for chain digitisation support of POS systems. The model is based on a literature study of existing maturity models, 
Plomp, M.G.A., Rijn, G. van, Batenburg, R.S. Chain digitisation support by point-of-sale systems: an analysis of the Dutch product software market. International Journal of Information

Technology and Management: 2012, 11(4), 257-272

combined with the specific characteristics of the retail sector and its value chain(s). Our model consists of two dimensions - backward and forward chain digitisation that hold four similar maturity levels: internal isolated, internal integrated, external linked and external integrated.

We operationalised our model through a set of functionality items and assessment rules, by which we can categorise POS systems on their level of chain digitisation. In practice, this operationalisation (and validation) of the model was conducted through a questionnaire and additional company visits of 79 Dutch vendors who market 86 different POS systems.

A main result of our analysis is that there is a great diversity among POS systems if they are assessed on the level of support for chain digitisation. Chain digitisation functionalities differ greatly. Another finding is that no POS system was found that supports external integrated forward chain digitisation. Apparently, this type of functionality is still very much 'something of the future'. This result indicates an interesting market opportunity for POS software developers. We conclude by stating that it is important that retailers have something to choose from. They should seriously consider what chain digitisation functionalities they will need and which POS system best fits those needs.

Comparing these results with related work is difficult, since we did not find many similar research efforts, as already indicated in the introduction of this paper. The scarce related studies that have been performed, often focus on the actual benefits of sharing POS data throughout the supply chain; see for instance, the simulation study of Croson and Donohue (2003). Also related are the results of a study on the actual chain digitisation maturity of the Dutch retail sector (Plomp and Batenburg, 2010). There it was found that in general, this maturity is above the sector average for the clothing branch, whereas the food branches lag behind. This corresponds with the results of the present study, which shows similar maturity levels for the available POS systems for these sectors. This leads to the interesting - albeit tentative finding that a relation exists between the maturity of what software is offered by vendors for a certain market and the maturity of that market itself. In order to substantiate this relationship and determine its causality, further research is needed. Two important limitations of our model should be mentioned here. First, as the model has been specifically designed for the retail sector, it is not necessarily applicable to POS systems outside of this sector. Although it can be argued that most POS systems are used within the retail sector, they are also being used in the catering/hospitality industry. In that industry there are POS systems with particular peripherals available, for instance, wireless pagers and electronic signature capture devices. It may prove difficult to position these POS systems within our maturity model. A clear second limitation of the present study is that we only looked at the Dutch vendor market, whereas the situation could be different in other countries. A point of discussion is the maturity assessment of the evaluated POS systems. This can be illustrated by two examples. First, there is one system that offers backward 'external integrated' functionalities, but is categorised at the 'external linked' level. The reason for this is that the system lacks support for automatic product updates. However, product updates are highly unusual in the specific branch this POS system was developed for. Because other business documents can be exchanged automatically through this specific POS system, its maturity can be considered as 'incomplete' 'external integrated'. 
Plomp, M.G.A., Rijn, G. van, Batenburg, R.S. Chain digitisation support by point-of-sale systems: an analysis of the Dutch product software market. International Journal of Information

Technology and Management: 2012, 11(4), 257-272

A second example of a maturity assessment issue is formed by most POS systems that connect to the chain digitisation initiative of the furniture branch. These are at the level of 'external linked' backward chain digitisation according to the maturity model. The initiative enables retailers to import product information and order automatically, but does not support electronic packing slips at this time. Therefore, POS systems are categorised at the third level of backward chain digitisation support, while they can also be considered as 'incomplete' 'external integrated'. Following these examples, it can be concluded that the rules for the fourth level of backward chain digitisation are strictly defined. For some specific cases, it could be argued that they are too strict. This would call for a concept of 'situational maturity', meaning that the 'best' level of maturity may be contingent on the specific situation, e.g., the branch the retailer is in. This could be a subject for further research.

Other future research endeavours could focus on extending the maturity model developed here to other POS system functionalities, e.g., administration, loyalty features or support of peripherals. With regard to the current model, both studies in other locations (i.e., an international comparison) and studies over time (i.e., a longitudinal study of the same POS vendors) would be of interest, to see whether there are differences between countries, and whether the POS system market matures over time in terms of chain digitisation enabling functionalities. If this research could find its way into practise, it could stimulate software suppliers to innovate their solutions, in turn leading to better POS systems for retailers. In our view, further exploring the role of software vendors in innovating value chains would be of great value.

\section{REFERENCES}

Alonso-Mendo, F., Fitzgerald, G. and Frias-Martinez, E. (2009) 'Understanding web site redesigns in small- and medium-sized enterprises (SMEs): a U.K-based study on the applicability of e-commerce stage models', European Journal of Information Systems, Vol. 18, No. 3, pp.264-279.

Becker, J. and Schütte, R. (2004) Handelsinformationssysteme, Redline, Frankfurt am Main, Germany.

Benbasat, I., Dexter, A.S., Drury, D.H. and Goldstein, R.C. (1984) 'A critique of the stage hypothesis: theory and empirical evidence', Communications of the ACM, Vol. 27, No. 5, pp.476-485.

Berger, C., Möslein, K., Piller, F. and Reichwald, R. (2005) 'Co-designing modes of cooperation at the customer interface: learning from exploratory research', European Management Review, Vol. 2, No. 1, pp.70-87.

Chen, H., Themistocleous, M. and Chiu, K-H. (2004) 'Approaches to supply chain integration followed by SMEs: an exploratory case study', Tenth Americas Conference on Information Systems, New York.

Chopra, S. and Meindl, P. (2004) Supply Chain Management: Strategy, Planning, and Operations, Prentice Hall, Upper Saddle River, New Jersey.

Clark, T. and Jones, R. (1999) 'Organisational interoperability maturity model for C2', Command and Control Research and Technology Symposium, Newport, Rhode Island.

Croson, R. and Donohue, K. (2003) 'Impact of POS data sharing on supply chain management: an experimental study', Production and Operations Management, Vol. 12, No. 1, pp.1-11.

Daft, R.L. (2001) Organizational Theory and Design, South-Western Educational Publishing, Cincinnati, Ohio.

Folinas, D., Manthou, V., Sigala, M. and Vlachopoulou, M. (2004) 'Evolution of a supply chain: cases and best practices', Internet Research: Electronic Networking Applications and Policy, Vol. 14, No. 4, pp.274-283. 
Plomp, M.G.A., Rijn, G. van, Batenburg, R.S. Chain digitisation support by point-of-sale systems: an analysis of the Dutch product software market. International Journal of Information

Technology and Management: 2012, 11(4), 257-272

Jansen, S., Finkelstein, A. and Brinkkemper, S. (2009) 'A sense of community: a research agenda for software ecosystems', 31st International Conference on Software Engineering, IEEE, Vancouver, British Columbia, Canada, pp.187-190.

Lee, H.L., Padmanabhan, V. and Whang, S. (1997) 'Information distortion in a supply chain: the bullwhip effect', Management Science, Vol. 43, No. 4, pp.546-558.

McLaren, T. (2006) 'A measurement model for web-enabled supply chain integration', 19th Bled eConference eValues, Bled, Slovenia.

Nolan, R.L. (1979) 'Managing the crises in data processing', Harvard Business Review, Vol. 57, No. 2, pp.115-126.

Pant, S. and Ravichandran, T. (2001) 'A framework for information systems planning for ebusiness', Logistics Information Management, Vol. 14, Nos. 1/2, pp.85-99.

Payne, W. (2002) 'The time for ERP?', Work Study, Vol. 51, No. 2, pp.91-93.

Plomp, M.G.A. and Batenburg, R.S. (2010) 'Measuring chain digitisation maturity: an assessment of Dutch retail branches', Supply Chain Management: An International Journal, Vol. 15, No. 3, pp.227-237.

Röcker, C. (2010) 'Chances and challenges of intelligent technologies in the production and retail sector', International Journal of Business and Economic Sciences, Vol. 2, No. 3, pp.150-161.

Schoenfeldt, T.I. (2008) A Practical Application of Supply Chain Management Principles, American Society for Quality Press, Milwaukee, Wisconsin.

Stair, R.M. and Reynolds, G.W. (2003) Fundamentals of Information Systems, Thomson/Course Technology, UK.

Subramani, M. and Walden, E. (2000) 'Economic returns to firms from business-to-business electronic commerce initiatives: an empirical examination', in Orlikwski, W., Ang, S., Weill, P., Krcmar, H. and DeGross, J.I. (Eds.): 21st International Conference on Information Systems, pp.229-241, Association for Information Systems, Brisbane, Australia.

Wang, Y.C.W., Chang, C-W. and Heng, M.S.H. (2004) 'The levels of information technology adoption, business network, and a strategic position model for evaluating supply chain integration', Journal of Electronic Commerce Research, Vol. 5, No. 2, pp.85-98.

Williamson, E.A. (2007) 'An evaluation of inter-organisational information systems development on business partnership relations', International Journal of Business Science and Applied Management, Vol. 2, No. 3, pp.36-50.

$\mathrm{Xu}, \mathrm{L}$. and Brinkkemper, S. (2007) 'Concepts of product software', European Journal of Information Systems, Vol. 16, No. 5, pp.531-541. 
Plomp, M.G.A., Rijn, G. van, Batenburg, R.S. Chain digitisation support by point-of-sale systems: an analysis of the Dutch product software market. International Journal of Information Technology and Management: 2012, 11(4), 257-272

\section{TABLE AND FIGURES}

Figure 1 The Retail H-model
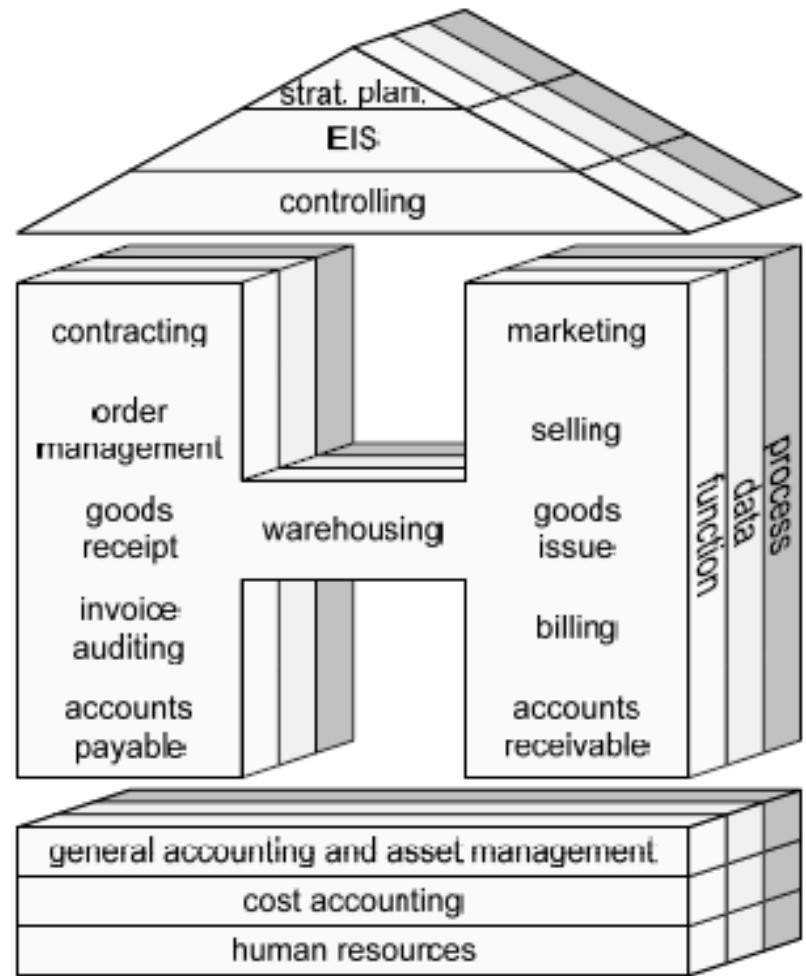

Source: Becker and Schütte (2004)

Figure 2 The retailer's position in the supply chain and the scope of backward and forward chain digitisation (CD)

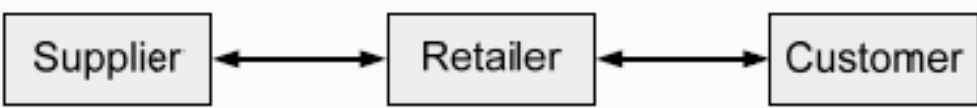


Plomp, M.G.A., Rijn, G. van, Batenburg, R.S. Chain digitisation support by point-of-sale systems: an analysis of the Dutch product software market. International Journal of Information

Technology and Management: 2012, 11(4), 257-272

Table 1 Comparison of five chain digitisation maturity models

\begin{tabular}{|c|c|c|c|c|c|}
\hline & Level 1 & Level 2 & Level 3 & Level 4 & Level 5 \\
\hline $\begin{array}{l}\text { Folinas } \\
\text { et al. (2004) }\end{array}$ & $\begin{array}{l}\text { Core logistics } \\
\text { activities } \\
\text { efficiency }\end{array}$ & $\begin{array}{c}\text { Coordination } \\
\text { of internal } \\
\text { organisational } \\
\text { processes }\end{array}$ & $\begin{array}{l}\text { Inter- } \\
\text { enterprise } \\
\text { business } \\
\text { exchanges }\end{array}$ & $\begin{array}{l}\text { Establishment of } \\
\text { dynamic networks } \\
\text { between virtual } \\
\text { organisations }\end{array}$ & \\
\hline $\begin{array}{l}\text { Wang et al. } \\
(2004)\end{array}$ & $\begin{array}{l}\text { Essential } \\
\text { functions }\end{array}$ & $\begin{array}{l}\text { Single } \\
\text { department/ } \\
\text { operation } \\
\text { process }\end{array}$ & $\begin{array}{c}\text { Cross } \\
\text { department/ } \\
\text { multi-process } \\
\text { integration }\end{array}$ & $\begin{array}{c}\text { Enterprise } \\
\text { integration process }\end{array}$ & $\begin{array}{c}\text { B2B } \\
\text { integration/ } \\
\text { collaborative } \\
\text { business }\end{array}$ \\
\hline $\begin{array}{l}\text { McLaren } \\
(2006)\end{array}$ & $\begin{array}{l}\text { Functional } \\
\text { focus }\end{array}$ & $\begin{array}{l}\text { Internal } \\
\text { integration }\end{array}$ & $\begin{array}{l}\text { Linked } \\
\text { network }\end{array}$ & $\begin{array}{l}\text { Integrated } \\
\text { network }\end{array}$ & $\begin{array}{l}\text { Optimised } \\
\text { network }\end{array}$ \\
\hline $\begin{array}{l}\text { Williamson } \\
(2007)\end{array}$ & $\begin{array}{l}\text { Elementary } \\
\text { IOS }\end{array}$ & $\begin{array}{l}\text { Intermediate } \\
\text { IOS }\end{array}$ & $\begin{array}{l}\text { Advanced } \\
\text { IOS }\end{array}$ & & \\
\hline $\begin{array}{l}\text { Schoenfeldt } \\
(2008)\end{array}$ & $\begin{array}{l}\text { Siloed } \\
\text { company }\end{array}$ & $\begin{array}{l}\text { Internal } \\
\text { integration }\end{array}$ & $\begin{array}{l}\text { One level of } \\
\text { integration/ } \\
\text { partnership }\end{array}$ & $\begin{array}{l}\text { Two levels of } \\
\text { integration }\end{array}$ & $\begin{array}{l}\text { Entire chain } \\
\text { integration }\end{array}$ \\
\hline
\end{tabular}

Figure 3 Maturity model for chain digitisation support of POS systems

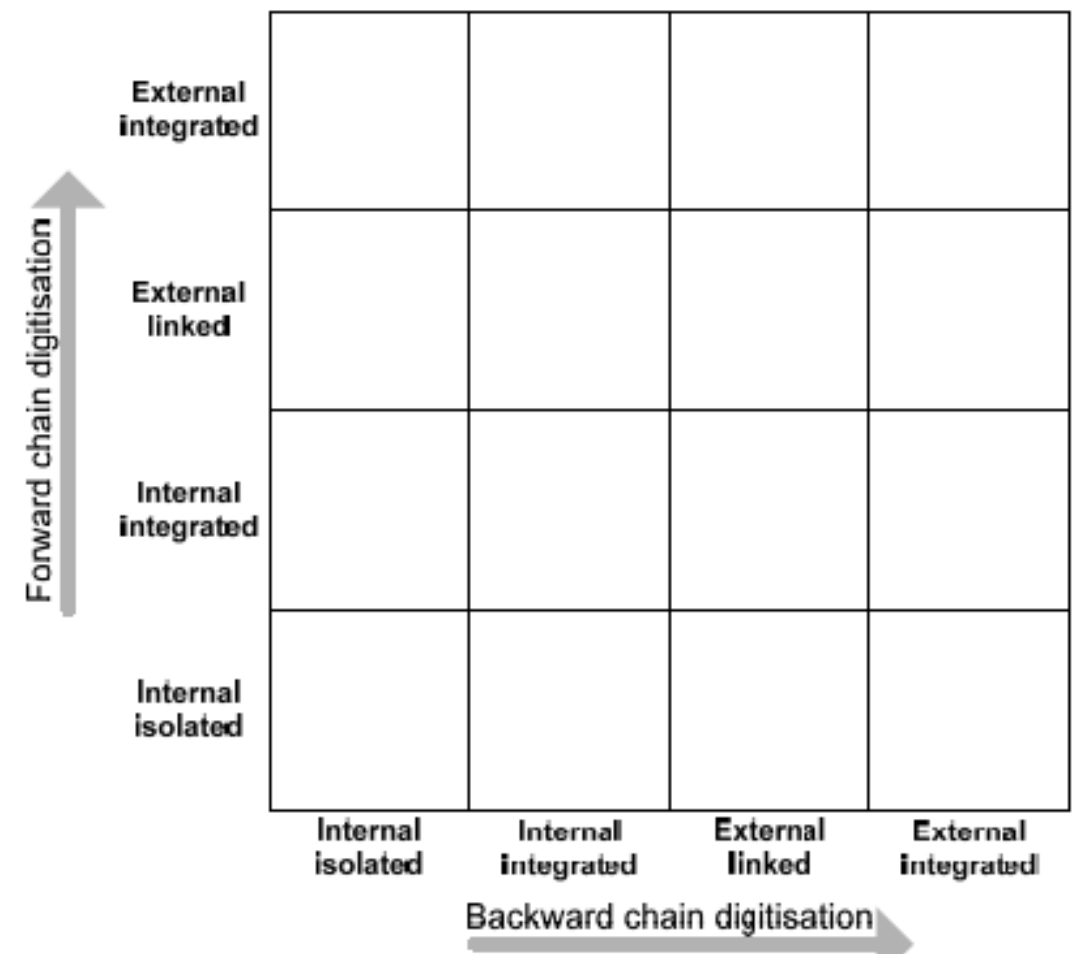


Plomp, M.G.A., Rijn, G. van, Batenburg, R.S. Chain digitisation support by point-of-sale systems: an analysis of the Dutch product software market. International Journal of Information Technology and Management: 2012, 11(4), 257-272

Table 2 POS chain digitisation maturity levels and their corresponding functionalities

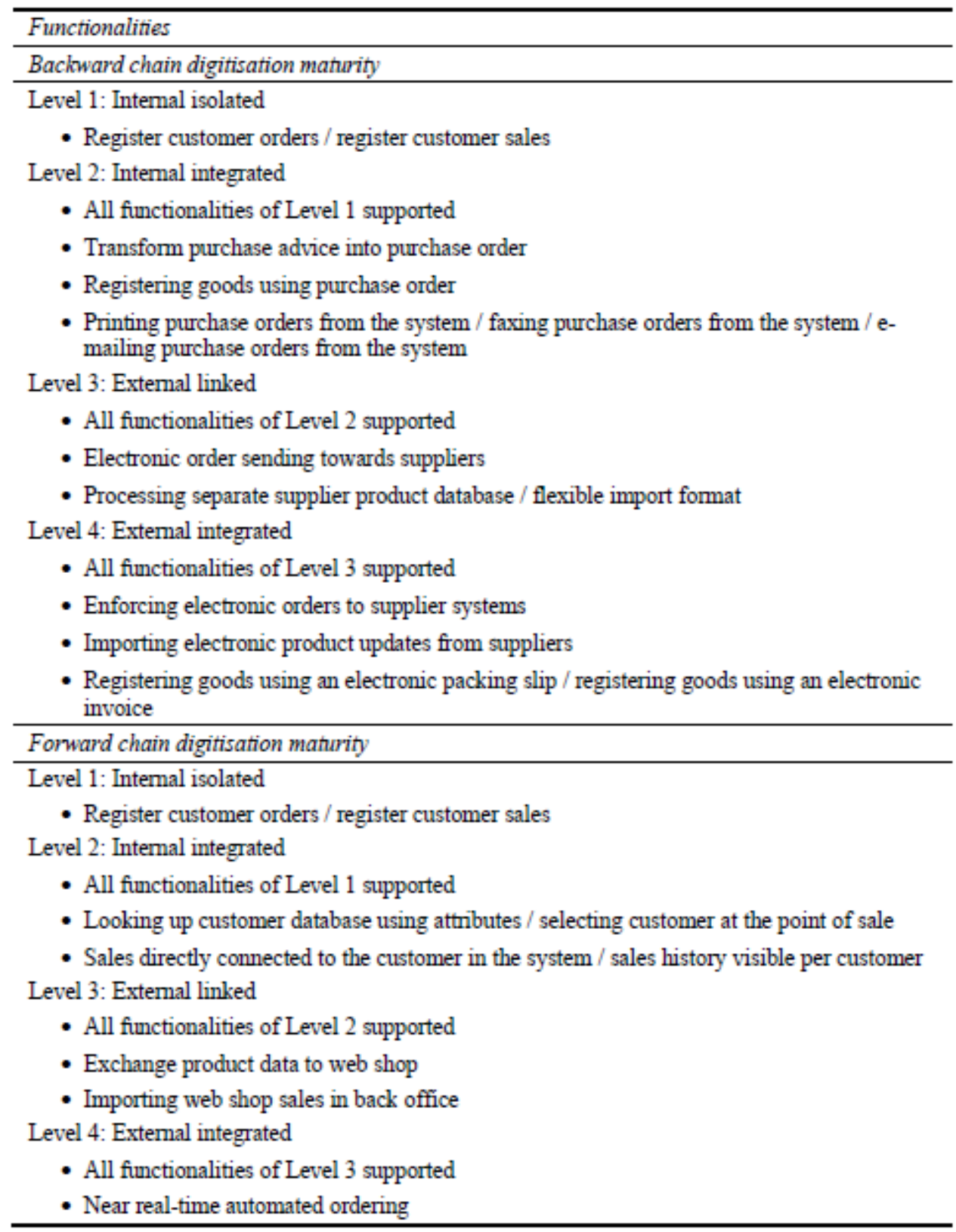


Plomp, M.G.A., Rijn, G. van, Batenburg, R.S. Chain digitisation support by point-of-sale systems: an analysis of the Dutch product software market. International Journal of Information Technology and Management: 2012, 11(4), 257-272

Figure 4 Position of POS systems available on the Dutch market in terms of forward and backward chain digitisation maturity

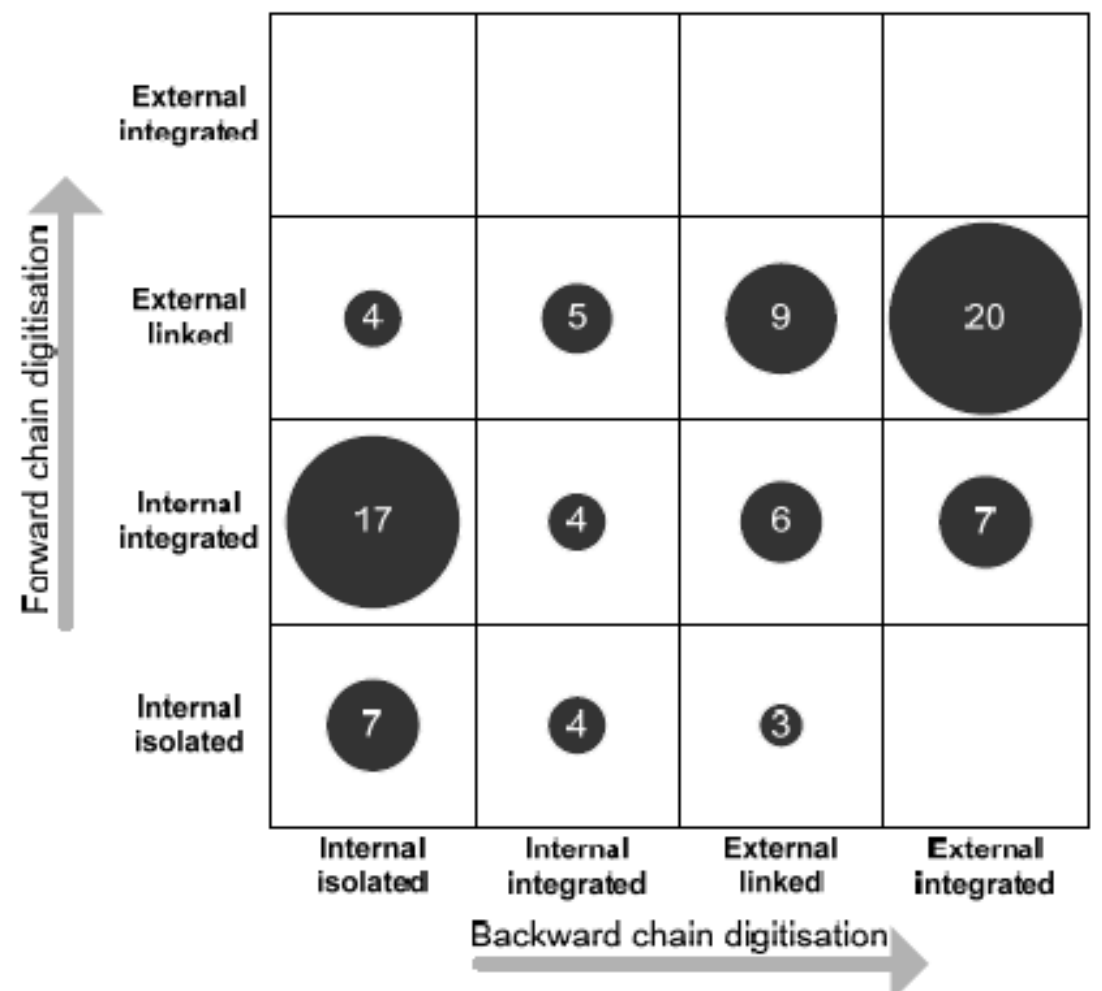

